\title{
Women's Health Outcomes After Traumatic Brain Injury
}

\author{
Angela Colantonio, Ph.D., O.T. Reg. (ON), ${ }^{1,2}$ Wanna Mar, M.A., Michael Escobar, Ph.D., \\ Karen Yoshida, Ph.D., Diana Velikonja, Ph.D., C.Psych., ${ }^{3}$ Sandro Rizoli, M.D., \\ Michael Cusimano, M.D., ${ }^{5}$ and Nora Cullen, M.D.,
}

\begin{abstract}
Background: Traumatic brain injury (TBI) is a major public health problem, yet little is known about how this injury may affect long-term outcomes unique to women. This research examined the health outcomes relevant to premenopausal women 5-12 years after injury.

Methods: This was a retrospective cohort study at eight participating acute care/rehabilitation facilities. Participants were consecutive eligible women with moderate to severe TBI. A follow-up interview assessed menstrual functioning, fertility, and pregnancy experiences before and after injury as well as cervical cancer screening. Demographic variables, self-rated general and mental health, and functional limitations were also collected. Injury-related information was abstracted from health records. Female control participants recruited were matched on age, education, and geographic location.

Results: Of the 104 women with TBI (W-TBI), 46\% experienced amenorrhea with duration of up to 60 months. Cycles became irregular for $68 \%$ of W-TBI after the injury. These findings were significantly different from those of controls. Among W-TBI, menstrual disturbances were associated with injury severity. No differences were shown between W-TBI and controls with respect to fertility, although significantly fewer W-TBI had one or more live births, and they reported more difficulties in the postpartum period than controls. W-TBI were less likely to have regular Pap smears and reported lower mental health, self-rated health, and function.

Conclusions: These findings inform prognosis after TBI for women and provide evidence for long-term monitoring of health outcomes and increased support after childbirth. More research is needed in this area, particularly with respect to the neuroendocrine system.
\end{abstract}

\section{Introduction}

$\mathbf{T}$

RAUMATIC BRAIN INJURY (TBI) is a leading cause of death and disability globally and, thus, is of major public health importance. ${ }^{1}$ TBI is more common than breast cancer, spinal cord injury, HIV/AIDS, and multiple sclerosis (MS) combined. $^{2-5}$ There are approximately 18,000 hospitalizations associated with a TBI diagnosis annually in Canada. ${ }^{6}$ The Centers for Disease Control and Prevention (CDC) estimates that $2 \%$ of the U.S. population lives with the effects of a TBI, of which about one third are women. ${ }^{7}$ Although men are at least twice as likely to sustain TBI, there is a very large population of women with TBI (W-TBI). Despite the large population affected, the health-related consequences of TBI unique to women have not been adequately studied. In particular, there is a paucity of information on the impact of TBI on the female reproductive system, and there is limited information on the use of health services relevant to W-TBI, such as cervical cancer screening, in Canada.

Little is known about the effect of TBI on women's reproductive health with respect to menstrual cycles, conception, and pregnancy long term, in contrast to injuries with much lower incidence, such as spinal cord injury. ${ }^{8,9}$ To date, only one study ${ }^{10}$ has investigated preinjury and postinjury menstrual and reproductive functioning in a small sample of 30 women who were 1 and 3 years postinjury and had completed inpatient rehabilitation. The authors found that many participants' menstrual functioning changed after injury, with a significant increase in skipped menses postinjury and a tendency toward more painful periods. However, because of the small number of women in

\footnotetext{
${ }^{1}$ University of Toronto, Toronto, Ontario, Canada.

${ }^{2}$ Toronto Rehabilitation Institute, Toronto, Ontario, Canada.

${ }^{3}$ McMaster University, Hamilton, Ontario, Canada.

${ }^{4}$ Sunnybrook Health Sciences Centre, Toronto, Ontario, Canada.

${ }^{5}$ St. Michael's Hospital, Toronto, Ontario, Canada.
} 
their study, the authors were not able to make any meaningful comparisons between preinjury and postinjury fertility.

The current investigation extends these findings in a number of ways. First, the inclusion of a control group in this study provides reference data for evaluating health outcomes after TBI. Second, participants were at least 5 years postinjury, which enables the assessment of longer-term health outcomes after TBI. Third, the sample size was larger and drawn from multiple centers across a wider geographical area. Lastly, we also addressed preventive health services specific to women as well as other measures of health and function. The information gained from this study is important, as it provides useful information specific to prognoses. In addition, it provides information on the neuroendocrine system that may lead to better treatment interventions or addressing barriers to care.

The main objective of this study was to investigate the longterm impact of moderate to severe TBI on women's health outcomes specific to premenopausal women, such as menstrual functioning, fertility, pregnancy experiences, and cervical cancer screening. General health, mental health, and physical function were also assessed.

\section{Materials and Methods}

\section{Participants}

This multicenter study was approved by the Research Ethics Board at all eight participating acute and rehabilitation centers across Ontario. Consecutive health records of female patients, aged 18-40 years at the time of TBI from January 1996 through December 2002, were reviewed for eligibility. Inclusion criteria for moderate to severe injury included having a Glasgow Coma Scale (GCS) score of $<13$ at the scene of injury or at hospital. ${ }^{11}$ If GCS scores were unavailable or if a person had a GCS $\geq 13$, eligibility was determined by evidence of loss of consciousness $>30$ minutes, posttraumatic amnesia of $>1$ day, or abnormal CT scans. ${ }^{12-14}$ Other eligibility criteria included living in the community, being able to communicate in English, and competence to sign a consent form.

A total of 367 women were identified as potentially eligible from health records; however, only 238 could be contacted within limits of the current privacy legislation. We were not able to determine how many identified cases did not meet eligibility criteria (eg., deceased/institutionalized or out of catchment area) at follow-up or how they differed from nonparticipants. Of the eligible women contacted, 104 consented to take part in the study.

W-TBI completed a face-to-face interview, during which a detailed questionnaire about women's health issues before and after injury was administered. Demographic and injuryrelated data were abstracted from the participants' health records after consent was obtained. All interviews and data abstraction were conducted by trained research staff.

The control group for this study consisted of 104 women with no prior history of a TBI, recruited through random digit dialing. They were matched with $\mathrm{W}-\mathrm{TBI}$ by age ( \pm 5 years), education ( \pm one level), and geographic location (first two digits of postal code). The controls completed only the interview portion of the study. Because of geographic and funding constraints, a small portion of the control women were interviewed by telephone $(n=14)$. The controls were asked about the same health issues within time periods corresponding to those used for the TBI participants. The time periods of 5-10 years ago and within the last 5 years were used as correlates of before and after injury, respectively.

\section{Measures}

Demographic information obtained included age at time of interview, living situation, marital status, number of children, education level, foreign-born status, employment history, and household income. Participants' postal codes were used to distinguish geographic location (i.e., urban vs. rural). Perceived supports on emotional, instrumental, and informational levels were also assessed in the questionnaire.

Perceived health and function. A 5-item self-rated health question from the Medical Outcomes Short Form-36 (MOS SF-36) ${ }^{15}$ was used to assess perceived health status at the time of the interview. Emotional well-being and fatigue items from the MOS SF-36 also were included. Functional status was measured in terms of limitations in basic activities of daily living (ADL) (e.g., bathing) and instrumental ADL (e.g., preparing meals) using subsets of the Older Americans Resources and Services (OARS) and the Multidimensional Functional Assessment Questionnaire. ${ }^{16}$ Self-reported measures of activity limitations and items from the MOS SF-36 have been found to be reliable and valid ${ }^{17,18}$ in TBI research. ${ }^{19}$

Injury-related variables. For W-TBI, information about age at time of injury, date of injury, length of unconsciousness, length of posttraumatic amnesia, GCS score, length of acute hospital stay, evidence of brain lesions on imaging report, mechanism of injury, and other injuries were abstracted from health records. An injury severity score (ISS) was subsequently generated, which is a standard measure to assess a person's overall injury level using scores from seven anatomical areas. ${ }^{20}$

Reproductive health. Questions were designed to explore the impact of TBI on women's menstrual cycles, fertility, and experiences with pregnancy. W-TBI were asked about the regularity and duration of their menstrual periods before and after their injury, specifically, if their menses were absent (amenorrhea), if cycles were irregular, if there were any changes in intensity of periods, and to indicate any other menses-related changes. ${ }^{21}$ Our definition of irregular cycles included occurrence of amenorrhea. W-TBI were also asked if they ever became or tried to become pregnant either before or after their injury. For those who responded positively, further questions covered such issues as difficulty conceiving, complications during pregnancy, miscarriages, abortions, and postpartum difficulties. ${ }^{22}$ For instance, we asked: Did you have any postpregnancy difficulties in the pregnancies that occurred after your brain injury? Women who answered yes to this question were asked to identify problems from the following list: inability to concentrate, depression, loss of independence, increased fatigue, spasms, mobility problems, pain, extremity edema, and other. The same questions were asked of controls using similar corresponding time points.

Cervical cancer screening. Validated questions, drawn from the Canadian Community Health Survey, ${ }^{23,24}$ were 
used to assess frequency of screening for cervical cancer. We conducted a reliability study on reproductive and cervical screening outcomes that yielded $77 \%-100 \%$ agreement on these items, with most with values $>85 \%{ }^{25}$

\section{Statistical analysis}

All data analyses were performed using Statistical Analysis System version 9.1 (SAS Institute, Cary, NC). Descriptive analyses, including frequency distributions and measures of cen- tral tendencies, were generated to describe the sample of W-TBI as well as their case-matched controls. Conditional logistic regression was used to analyze the matched pairs. The $p$ values were based on the Score test or the McNemar's test. These two tests are the same if the variables have two levels; however, only the score test is relevant for variables with more than two levels. When the variable has more than two levels, such as education, the odds ratio (OR) is for a change in one level of the ordinal score, assuming the scores are linear. The confidence intervals $(\mathrm{CI})$ from the OR are calculated from the profile

Table 1. Demographic Characteristics of Women with Traumatic Brain Injury and Control Groups

\begin{tabular}{|c|c|c|c|c|c|c|c|}
\hline \multirow[b]{2}{*}{ Variable } & \multicolumn{2}{|c|}{$W-T B I(\mathrm{n}=104)$} & \multicolumn{2}{|c|}{ Controls $(\mathrm{n}=104)$} & \multirow[b]{2}{*}{$O R^{\mathrm{a}}$} & \multirow[b]{2}{*}{$C I^{\mathrm{b}}$} & \multirow[b]{2}{*}{$\mathrm{p}$ value $^{\mathrm{c}}$} \\
\hline & $\mathrm{n}$ & $\%$ & $\mathrm{n}$ & $\%$ & & & \\
\hline \multicolumn{8}{|l|}{ Level of education at follow-up } \\
\hline University/college & 73 & 70 & 80 & 77 & \multirow[t]{3}{*}{0.63} & \multirow[t]{3}{*}{$(0.30-1.23)$} & \multirow[t]{3}{*}{0.18} \\
\hline High school & 23 & 22 & 17 & 16 & & & \\
\hline Some high school/elementary & 8 & 8 & 7 & 7 & & & \\
\hline \multicolumn{8}{|l|}{ Country of birth } \\
\hline Canada & 87 & 84 & 93 & 89 & \multirow[t]{2}{*}{0.57} & \multirow[t]{2}{*}{$(0.22-1.33)$} & \multirow[t]{2}{*}{0.20} \\
\hline Foreign & 17 & 16 & 11 & 11 & & & \\
\hline \multicolumn{8}{|l|}{ Marital status before injury } \\
\hline No & 67 & 64 & 36 & 35 & \multirow[t]{2}{*}{0.16} & \multirow[t]{2}{*}{$(0.06-0.36)$} & \multirow[t]{2}{*}{$<0.0001$} \\
\hline Yes & 37 & 36 & 68 & 65 & & & \\
\hline \multicolumn{8}{|l|}{ Marital status at follow-up } \\
\hline No & 55 & 53 & 21 & 20 & \multirow[t]{2}{*}{0.24} & \multirow[t]{2}{*}{$(0.12-0.46)$} & \multirow[t]{2}{*}{$<0.0001$} \\
\hline Yes & 49 & 47 & 83 & 80 & & & \\
\hline \multicolumn{8}{|l|}{ Marital status change } \\
\hline Yes before and No after & 9 & 8.7 & 7 & 6.7 & 0.87 & $(0.47-1.58)$ & 0.78 \\
\hline No before and Yes after & 21 & 20 & 22 & 21 & & & \\
\hline No change & 74 & 71 & 75 & 72 & & & \\
\hline Social support available & & & & & & & \\
\hline Emotional support & 94 & 90 & 102 & 98 & 0.11 & $(0.006-0.59)$ & 0.01 \\
\hline Instrumental support & 99 & 95 & 99 & 95 & 1 & $(0.28-3.60)$ & 1 \\
\hline Financial support & 90 & 87 & 103 & 99 & 0.07 & $(0.004-0.36)$ & 0.0008 \\
\hline Informational support & 96 & 92 & 102 & 98 & 0.25 & $(0.04-1.00)$ & 0.06 \\
\hline Employment status before injury & & & & & & & \\
\hline Yes & 88 & 85 & 90 & 87 & 0.83 & $(0.35-1.93)$ & 0.67 \\
\hline No & 16 & 15 & 14 & 13 & & & \\
\hline Employment status at follow-up & & & & & & & \\
\hline Yes & 62 & 60 & 89 & 86 & 0.29 & $(0.14-0.57)$ & 0.001 \\
\hline No & 42 & 40 & 15 & 14 & & & \\
\hline Employment status change & & & & & & & \\
\hline Yes before and No after & 38 & 37 & 12 & 12 & 0.47 & $(0.27-0.77)$ & 0.003 \\
\hline No before and Yes after & 12 & 11 & 11 & 10 & & & \\
\hline No change & 54 & 52 & 81 & 78 & & & \\
\hline Household income ${ }^{\mathrm{d}}$ & & & & & & & \\
\hline$<19,999$ & 17 & 18 & 0 & 0 & 0.71 & $(0.58-0.83)$ & $<0.0001$ \\
\hline $20,000-29,999$ & 5 & 5 & 9 & 10 & & & \\
\hline $30,000-39,999$ & 14 & 15 & 4 & 4 & & & \\
\hline $40,000-49,999$ & 8 & 9 & 7 & 8 & & & \\
\hline $50,000-59,999$ & 10 & 11 & 10 & 11 & & & \\
\hline $60,000-69,999$ & 9 & 10 & 7 & 8 & & & \\
\hline$\geq 70,000$ & 29 & 32 & 55 & 60 & & & \\
\hline & Mean & $S D$ & Mean & $S D$ & & & \\
\hline Age at follow-up & 35.2 & 7.6 & 35.4 & 8 & 0.97 & $(0.85-1.09)$ & 0.58 \\
\hline
\end{tabular}

${ }^{\mathrm{a}} \mathrm{OR}$ is based on matched pair analysis/conditional logistic regression, with the control group as the reference group. When a variable has more than two levels (eg., education), the OR is for a change in one level of the ordinal score, assuming a linear relationship between levels.

${ }^{b} \mathrm{CI}$ is calculated from the profile likelihood for the conditional regression.

${ }^{c} p$ value from the Score/McNemar statistics. The Score test and the McNemar test are the same if the variables are dichotomized.

${ }^{d}$ The unit of change for household income for the OR is one level of income, which is usually $\$ 10,000$. This also assumes that the relationship of the income levels is linear.

$\mathrm{CI}$, confidence interval; OR, odds ratio; W-TBI, women with traumatic brain injury. 
likelihood from the conditional logistic regression. For pregnancy outcomes, the matching was broken and only analyzed as a simple regression because there were only 13 relevant pairs for analyses. Logistic regression was used to assess correlations between severity of injury measures and key outcomes.

\section{Results}

\section{Sociodemographic characteristics}

Table 1 summarizes the demographic profile of the W-TBI and control groups. With respect to the W-TBI group, the mean age at time of injury was 27.5 years, standard deviation (SD) 7.5. The follow-up period ranged from 4.7 to 12.2 years postinjury (mean 7.8 years). At the time of interview, the mean age was 35.2 (SD 7.6) years, with a range of 24-50 years. Most $\mathrm{W}$-TBI were well educated, with $70 \%$ having postsecondary education at the time of follow-up. The majority were white (69\%), Canadian-born (84\%), and urban-dwelling (76\%).

As expected because of matching, W-TBI and controls did not differ significantly on age and education. A significantly higher percentage of W-TBI were not married before injury (64\%) compared with controls $5-10$ years before the interview (35\%). More W-TBI (53\%) were also unmarried after injury compared with controls (20\%) in a similar time frame. Change in marital status was not significant, indicating that marital status remained stable after injury. W-TBI were less likely to be employed at the time of the interview compared with controls, despite similar employment rates before injury. Approximately $37 \%$ of W-TBI became unemployed after injury compared with significantly fewer controls (12\%) within a similar time period. Household income was significantly lower among W-TBI, whereas no control women had incomes $<\$ 19,000$ and most had incomes of $\geq \$ 70,000$. Further comparison of income levels revealed that controls were three times more likely to have more income than W-TBI. In addition, significantly more W-TBI indicated they lacked financial and emotional support, which were among the areas of perceived support examined.

TABle 2. InJury Characteristics of Women With TRAumatic Brain INJURY

\begin{tabular}{lcc}
\hline & Mean & SD \\
\hline Age at time of injury & 27.5 & 7.5 \\
Acute LOS & 25 & 21.8 \\
Injury Severity Score & 23.8 & 10.5 \\
& $\mathrm{n}$ & $\%$ \\
\hline GCS score & & \\
3-8 & 71 & 68.3 \\
9-12 & 26 & 25.0 \\
13-15 & 5 & 4.8 \\
Unknown & 2 & 1.9 \\
Mechanism of TBI & 79 & 76.0 \\
Automobile & 10 & 9.6 \\
Pedestrian & 8 & 7.7 \\
Fall & 7 & 6.7 \\
Blow to the head/other & & \\
\hline
\end{tabular}

GCS, Glasgow Coma Score; LOS, length of stay; SD, standard deviation; TBI, traumatic brain injury; W-TBI, women with TBI.

\section{Injury-related variables}

Table 2 shows that $68 \%$ of the W-TBI in the study had severe brain injuries. The 5 women included with a GCS score of $\geq 13$ and the 2 women with unknown GCS scores were found to have other evidence of moderate to severe brain injury. These women had posttraumatic amnesia for $>1$ day, had documented lesions (frontal lobe or temporal/parietal lobe involvement), with $1 \mathrm{~W}$-TBI having a subdural hematoma. The primary mechanism of injury was motor vehicle related $(76 \%)$.

\section{Perceived health and function}

Table 3 shows significantly lower ratings on overall perceived health, emotional well-being, energy/fatigue, and physical function among W-TBI.

\section{Reproductive health}

Menstrual periods. The mean duration of amenorrhea was 6.5 months, with a range of 1-60 months. There was 1 participant whose periods stopped at time of injury and had not returned by time of interview. Significantly fewer W-TBI (49\%) reported changes in menstrual flow after injury compared with their control counterparts $(64 \%, p=0.018)$. Matched case-control conditional regression analyses showed that W-TBI were 21 times more likely than controls to report amenorrhea after injury; for those with regular cycles, W-TBI were 6 times more likely to experience irregular cycles. Among W-TBI, amenorrhea was associated with lower GCS scores (OR 0.83, CI 0.72-0.93, $\mathrm{p}=0.0025$ ), higher ISS, and longer length of acute hospital stay $(p<0.001)$ (Table 4$)$. Irregular periods emerging after the injury were significantly associated with higher ISS only.

Fertility/pregnancy. Of W-TBI $(n=29), 28 \%$ indicated that they tried to conceive or became pregnant after their TBI vs. $35 \%$ of controls $(n=36)$ during a comparable time period $(p=0.26)$. Hence, the subgroups for these analyses are smaller in size (Table 3).

No significant group differences were found in terms of difficulty conceiving $(p=0.40)$ or difficulties during pregnancy after injury $(p=0.14)$ (Table 5$)$. Of those who became pregnant, however, significantly fewer W-TBI had one or more live births compared with controls $(p=0.0045)$. W-TBI were also more likely to report postpregnancy difficulties in the pregnancies that occurred after the brain injury compared with controls in the equivalent time period. The 12 women reported the following: increased fatigue $(n=8)$, pain $(n=6)$, depression $(n=5)$, mobility problems $(n=3)$, inability to concentrate $(n=4)$, and lower extremity edema $(n=1)$. Three women who did not report depression reported "feeling the blues," and 1 woman reported hip pain/headaches.

\section{Cervical cancer screening}

The majority of W-TBI and controls reported having their last Pap smear within the recommended time interval (Table 3). There was a trend showing that W-TBI were more likely than controls to have their last Pap smear $>3$ years ago $(p=0.06)$.

\section{Discussion}

To our knowledge, this study is the most comprehensive investigation to date of women's unique health issues after 
Table 3. Comparison of Women with Traumatic Brain Injury and Controls on Main Health Outcomes

\begin{tabular}{|c|c|c|c|c|c|c|c|}
\hline \multirow[b]{2}{*}{ Variable } & \multicolumn{2}{|c|}{$W-T B I(\mathrm{n}=104)$} & \multicolumn{2}{|c|}{ Controls $(\mathrm{n}=104)$} & \multirow[b]{2}{*}{$O R$} & \multirow[b]{2}{*}{$C I$} & \multirow[b]{2}{*}{$\mathrm{p}$ value } \\
\hline & $\mathrm{n}$ & $\%$ & $\mathrm{n}$ & $\%$ & & & \\
\hline \multicolumn{8}{|l|}{ Menstrual cycles } \\
\hline Became irregular ${ }^{a}$ & & & & & 6.41 & $(2.72-18.87)$ & $<0.0001$ \\
\hline Yes & 45 & 68 & 18 & 27 & & & \\
\hline No & 21 & 32 & 48 & 73 & & & \\
\hline Stopped for awhile & & & & & 20.5 & $(6.31-125.78)$ & $<0.0001$ \\
\hline Yes & 47 & 46 & 8 & 8 & & & \\
\hline No & 55 & 54 & 94 & 92 & & & \\
\hline \multicolumn{8}{|l|}{ Fertility } \\
\hline Tried/became pregnant before injury & & & & & 0.31 & $(0.14-0.63)$ & 0.0012 \\
\hline Yes & 44 & 42 & 64 & 62 & & & \\
\hline No & 60 & 58 & 40 & 38 & & & \\
\hline Tried/became pregnant after injury & & & & & 0.70 & $(0.26-1.31)$ & 0.26 \\
\hline Yes & 29 & 28 & 36 & 35 & & & \\
\hline No & 75 & 72 & 68 & 65 & & & \\
\hline \multicolumn{8}{|l|}{ Cervical cancer screening } \\
\hline Last Pap smear $<3$ years ago & 80 & 85 & 88 & 94 & 2.6 & $(0.98-8.10)$ & 0.059 \\
\hline Last Pap smear $\geq 3$ years ago & 14 & 15 & 6 & 6 & & & \\
\hline Activity limitations & & & & & & & \\
\hline Daily & & & & & $\mathrm{b}$ & $\mathrm{b}$ & $\mathrm{b}$ \\
\hline No limitation & 94 & 90 & 104 & 100 & & & \\
\hline One or more limitations & 10 & 10 & 0 & 0 & & & \\
\hline Instrumental & & & & & 12.25 & $(5.00-40.56)$ & $<0.0001$ \\
\hline No limitation & 53 & 51 & 98 & 94 & & & \\
\hline One or more limitations & 51 & 49 & 6 & 6 & & & \\
\hline Self-rated overall health & & & & & 2.03 & $(1.49-2.88)$ & $<0.0001$ \\
\hline Excellent & 19 & 18 & 33 & 32 & & & \\
\hline Very good & 27 & 26 & 50 & 48 & & & \\
\hline Good & 36 & 35 & 17 & 16 & & & \\
\hline Fair/poor & 22 & 21 & 4 & 4 & & & \\
\hline Self-rated mental health ${ }^{c}$ & Mean & $S D$ & Mean & $S D$ & & & \\
\hline Emotional well-being & 66 & 22 & 76 & 16 & 0.75 & $(0.63-0.89)$ & 0.0004 \\
\hline Energy/fatigue & 50 & 25 & 63 & 18 & 0.75 & $(0.65-0.87)$ & $<0.0001$ \\
\hline
\end{tabular}

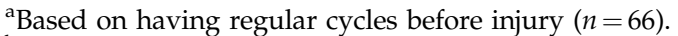

${ }^{\mathrm{b}}$ The estimate of the OR (including CI and $p$ value) could not be calculated because none of the controls had daily activity limitations.

${ }^{\mathrm{c}} \mathrm{OR}$ was estimated for change in 10 points on either emotional well-being or energy/fatigue scales.

$\mathrm{CI}$, confidence interval; OR, odds ratio; W-TBI, women with traumatic brain injury.

TBI and the first to document these outcomes with such a long range of follow-up. We found that W-TBI were more likely to report menstrual changes after injury, including irregular cycles and amenorrhea, compared with women without TBI within a similar time frame. Among W-TBI who experienced amenorrhea, it was generally transient, with the average time postinjury until menses resumed being 6.5 months. No significant differences were found between $\mathrm{W}$-TBI and controls with respect to fertility and pregnancy-related difficulties. However, significantly fewer W-TBI than controls reported having one or more live births after injury, and significantly more $\mathrm{W}$-TBI than controls indicated postpartum difficulties after their most recent pregnancy. In addition, $\mathrm{W}$-TBI reported lower levels of perceived health (including mental health), physical function, perceived support, and income and were less likely to be married before and after injury. W-TBI were also less likely to obtain Pap smears within the recommended time interval, but this difference only approached significance $(p<0.06)$.

Our findings regarding menstrual functioning are consistent with those of Ripley et al., ${ }^{10}$ who reported a significant increase in skipped periods after injury among women with mild to severe TBI. Injury severity was a significant predictor of amenorrhea among W-TBI in our study. With regard to cervical cancer screening, our results tend to support previous studies showing that women with cognitive and physical disabilities were less likely to have routine cervical cancer screening. ${ }^{26-28}$ With a larger sample, one could potentially see a larger effect.

There are many possible reasons for $\mathrm{W}$-TBI having fewer children and experiencing more problems after childbirth. A previous small study of TBI survivors many years postinjury showed that parents with a history of a TBI experienced more symptoms of depression relative to a comparison group without TBI. ${ }^{29}$ More depressive symptoms and fatigue, in fact, were reported in our study among W-TBI. In addition, $\mathrm{W}$-TBI may not be able to return to previous roles, putting more strain on other family members, such as spouses. Longterm social isolation is also not uncommon after a TBI. ${ }^{30,31}$ The physical and cognitive demands of rearing a child may be such that W-TBI may not be in a position to cope with as many children or as well as they would have otherwise. They may not be able to return to work in the same capacity as before, thus, financial factors may contribute to a conscious 
Table 4. Severity of Injury and Outcome Measures: LOGISTIC REgRession ANALyses

\begin{tabular}{lccc}
\hline Severity measure & OR & $95 \%$ CI & p value \\
\hline Periods stopped for a while & \multicolumn{4}{c}{} \\
GCS & 0.83 & $0.72,0.93$ & 0.003 \\
ISS & 1.07 & $1.03,1.12$ & 0.001 \\
Length of stay & 1.04 & $1.01,1.06$ & 0.004 \\
Periods became irregular when previously regular & \\
GCS & 0.94 & $0.81,1.08$ & 0.347 \\
ISS & 1.08 & $1.03,1.15$ & 0.001 \\
Length of stay & 1.03 & $1.00,1.06$ & 0.066 \\
\hline
\end{tabular}

CI, confidence interval; GCS, Glasgow Coma Scale; ISS, Injury Severity Score; OR, odds ratio.

decision not to have more children. Indeed, our study found that W-TBI had a significantly higher rate of unemployment and lower household incomes after the injury, which has been well documented in the literature. ${ }^{19}$

Study limitations included a lower than expected tracing and participation rate. We were not able to compare the characteristics of respondents with the characteristics of nonrespondents in order to assess the degree of generalizability, as we did not have consent from nonrespondents to access this information. Our TBI participants were probably more educated and of higher socioeconomic status (SES) than nonparticipants, which could potentially affect outcomes, such as cervical cancer screening, more than biological outcomes, such as menstrual cycles. Our control participants, however, were matched on educational level and were also of higher SES, as one would expect of a volunteer population. We also did not collect more biological information, which could have helped to explain menstrual disruption. We acknowledge that W-TBI may be potentially more likely to have difficulty recalling events as a result of disturbances in longterm and short-term memory.

TBI is one of the etiologies of hypopituitarism, which has been found to affect $25 \%-59 \%$ of patients several months and even years after head trauma. ${ }^{32-35}$ Pituitary abnormalities are not entirely unexpected after TBI, given the pituitary's vulnerable location in the brain and its tenuous blood supply. ${ }^{36}$ Low levels of sex hormones associated with hypopituitarism can also cause amenorrhea and other menstrual disorders 37,38 and can have wide-ranging negative effects on quality of life, mental health, and overall recovery. ${ }^{39}$ Unfortunately, screening for hypopituitarism after TBI is not commonly done, and, thus, hypopituitarism is relatively underdiagnosed in the TBI population. ${ }^{32,35}$ Menstrual difficulties post-TBI may be a sign of neuroendocrine irregularities, which may affect other health issues, such as cognition and mood. These relationships, however, need to be studied further. For instance, a prospective study could be conducted where participants would be asked to record menstrual functioning/reproductive health through the use of diaries and at the same time have hormonal assays performed.

Table 5. Comparison of Women with Traumatic Brain Injury and Controls on Fertility and Pregnancy

\begin{tabular}{|c|c|c|c|c|c|c|c|}
\hline \multirow[b]{2}{*}{ Variable } & \multicolumn{2}{|c|}{$W-T B I$} & \multicolumn{2}{|c|}{ Controls } & \multirow[b]{2}{*}{ OR } & \multirow[b]{2}{*}{$C I$} & \multirow[b]{2}{*}{$\mathrm{p}$ value } \\
\hline & $\mathrm{n}$ & $\%$ & $\mathrm{n}$ & $\%$ & & & \\
\hline Difficulty conceiving before injury & $(n=44)$ & & $(n=64)$ & & 0.36 & $(0.10-1.09)$ & 0.07 \\
\hline Yes & 4 & 9 & 14 & 22 & & & \\
\hline No & 40 & 91 & 50 & 78 & & & \\
\hline Difficulty conceiving after injury & $(n=29)$ & & $(n=36)$ & & 1.58 & $(0.54-4.71)$ & 0.40 \\
\hline Yes & 10 & 34 & 9 & 25 & & & \\
\hline No & 19 & 66 & 27 & 75 & & & \\
\hline \multicolumn{8}{|l|}{ Pregnancy before injury } \\
\hline Difficulties during pregnancy & $(n=42)$ & & $(n=62)$ & & 1.09 & $(0.47-2.46)$ & 0.85 \\
\hline Yes & 15 & 36 & 21 & 34 & & & \\
\hline No & 27 & 64 & 41 & 66 & & & \\
\hline Postpartum difficulties & $(n=42)$ & & $(n=62)$ & & 0.46 & $(0.17-1.13)$ & 0.09 \\
\hline Yes & 8 & 19 & 21 & 34 & & & \\
\hline No & 34 & 81 & 41 & 66 & & & \\
\hline Live births (one or more) & $(n=42)$ & & $(n=62)$ & & 0.66 & $(0.12-3.73)$ & 0.62 \\
\hline Yes & 39 & 93 & 59 & 95 & & & \\
\hline $\mathrm{No}$ & 3 & 7 & 3 & 5 & & & \\
\hline \multicolumn{8}{|l|}{ Pregnancy after injury } \\
\hline Difficulties during pregnancy & $(n=26)$ & & $(n=35)$ & & 2.18 & $(0.77-6.36)$ & 0.14 \\
\hline Yes & 13 & 50 & 11 & 31 & & & \\
\hline No & 13 & 50 & 24 & 69 & & & \\
\hline Postpartum difficulties & $(n=24)$ & & $(n=34)$ & & 3.25 & $(1.07-10.40)$ & 0.04 \\
\hline Yes & 12 & 50 & 8 & 24 & & & \\
\hline No & 12 & 50 & 26 & 76 & & & \\
\hline Live births (one or more) & $(n=26)$ & & $(n=35)$ & & 0.15 & $(0.03-0.57)$ & 0.0045 \\
\hline Yes & 16 & 62 & 32 & 91 & & & \\
\hline No & 10 & 38 & 3 & 9 & & & \\
\hline
\end{tabular}

These variables were not analyzed as matched pairs but as simple logistic regressions. These analyses were only applicable to those who were pregnant. Using matched pairs within this subsample would have resulted in a very small sample.

$\mathrm{CI}$, confidence interval; OR, odds ratio; W-TBI, women with traumatic brain injury. 
Our study provides important novel information about the impact of TBI specifically on women's health issues and has important implications for health professionals working with W-TBI. Given the high frequency of posttraumatic amenorrhea, screening for menstrual irregularities should be routinely conducted for women after TBI, with gynecological referrals as required. Our study findings indicate that the ability to carry a child to term is not affected by TBI, which provides prognostic information that is often requested after injury. We also found that W-TBI have fewer children and are at increased risk of postpartum difficulties. The results support prior research ${ }^{19}$ that shows that women may require ongoing long-term support after TBI because of significantly lower perceived mental health, energy levels, physical function, social support, and income. Health professionals working with these women need to address the medical and social needs that we have shown can frequently affect female survivors of TBI. Possible programs include screenings for menstrual disturbances in both the acute and postacute stage, early intervention programs, and prevention programs for pregnancy after TBI that involve assessment of both personal and environmental resources needed. Finally, there is a role for healthcare providers as advocates for greater supports specific to W-TBI.

\section{Acknowledgments}

We thank our collaborators and the administrative staff who provided support at the participating sites. We also thank the Institute for Social Research at York University for their assistance with recruiting controls, the interviewers for their assistance with data collection, and Junlang Yin for performing the statistical analyses. The study received ethics approval from the University of Toronto and from the research ethics boards of the eight participating centers: Toronto Rehabilitation Institute, Sunnybrook Health Sciences Centre, St. Michael's Hospital, Bridgepoint Health, Hamilton General Hospital, Chedoke Hospital, Thunder Bay Regional Health Sciences Centre, Brain Injury Services of Northern Ontario. We also sincerely thank the participants in this research study and Alice Bellavance. Funding for the study was obtained from the Canadian Institutes for Health Research grant 200903MOP, The Toronto Rehabilitation Institute, and a grant from the Ministry of Health and Long Term Care to the Toronto Rehabilitation Institute. This report was presented at the American Congress of Rehabilitation Medicine Annual Meeting, October 2009, where it received a best paper award (first place).

\section{Disclosure Statement}

The authors have no conflicts of interest to report.

\section{References}

1. World Health Organization. Neurological disorders: Public health challenges. Geneva:WHO;2007. Available at www. who.int/mental_health/en/

2. Canadian Institute for Health Information. The burden of neurological diseases, disorders and injuries in Canada. Ottawa, ON: CIHI, 2007.

3. Canadian Cancer Society/National Institute of Canada. Canadian cancer statistics, 2008. Toronto, Canada: Author, 2008. Available at www.cancer.ca/statistics.
4. Public Health Agency of Canada. HIV/AIDS epi updates, November 2007. Surveillance and Risk Assessment Division, Centre for Infectious Disease Prevention and Control. Public Health Agency of Canada, 2007. Available at www.phac-aspc .gc.ca.

5. Canadian Paraplegic Association. SCI facts, 2008. Available at www.canparaplegic.org/en/

6. Canadian Institute for Health Information. Brain injuries in canada: A decade of change (1994/95 to 2003/2004). Ottawa, ON: CIHI, 2006.

7. Thurman D, Alverson C, Dunn K, Guerrero J, Sniezek J. Traumatic brain injury in the United States: A public health perspective. J Head Trauma Rehabil 1999;14:602-615.

8. Sipksi ML. The impact of spinal cord injury on female sexuality, menstruation and pregnancy: A review of the literature. J Am Paraplegic Soc 1991;14:122-126.

9. Jackson AB, Wadley V. A multicenter study of women's selfreported reproductive health after spinal cord injury. Arch Phys Med Rehabil 1999;80:1420-1428.

10. Ripley DL, Harrison-Felix C, Sendroy-Terrill M, Cusick CP, Dannels-McClure A, Morey $\mathrm{C}$. The impact of female reproductive function on outcomes after traumatic brain injury. Arch Phys Med Rehabil 2008;89:1090-1096.

11. Teasdale G, Jennett B. Assessment of coma and impaired consciousness. Lancet 1974;2:81-84.

12. American Congress of Rehabilitation Medicine: Definition of mild traumatic brain injury. J Head Trauma Rehabil 1993;8: 86-87.

13. De Kruijk JR, Twijnstra A, Leffers P. Diagnostic criteria and differential diagnosis of mild traumatic brain injury. Brain Injury 2001;15:99-106.

14. Carroll LJ, Cassidy, JD, Holm L, Kraus J, Coronado VG. Methodological issues and research recommendations for mild traumatic brain injury: The WHO Collaborating Center Task Force on mild traumatic brain injury. J Rehabil Med 2004;43(Suppl):113-125.

15. Ware JE. SF-36. Health survey manual and interpretation guide. Boston: The Health Institute, New England Medical Center, 1993.

16. Fillenbaum G. Reliability and validity of the OARS Multidimensional Functional Assessment Questionnaire. In: Pfeiffer E, ed. Multidimensional Functional Assessment: the OARS methodology: A manual. Durham, NC: Duke University Center for the Study of Aging and Human Development, 1975.

17. Findler M, Cantor J, Haddad L, Gordon W, Ashman T. The reliability and validity of the SF-36 health survey questionnaire for use with individuals with traumatic brain injury. Brain Injury 2001;15:715-723.

18. Smith P, Illig S, Fielder R, Hamilton B, Ottenbacher K. Intermodel agreement of follow-up telephone functional assessment using the functional independence measure in patients with stroke. Arch Phys Med Rehabil 1996;77:431-435.

19. Colantonio A, Ratcliff G, Chase S, Kelsey S, Escobar, M, Vernich L. Long-term outcomes after moderate to severe traumatic brain injury. Disabil Rehabil 2004;26:253-261.

20. Baker SP, O'Neill B, Haddon W Jr, Long WB. The Injury Severity Score: A method for describing patients with multiple injuries and evaluating emergency care. I Trauma 1974;14:187-196.

21. Solomon CG, Hu FB, Duanif A, et al. Menstrual cycle irregularity and risk for future cardiovascular disease. I Clin Endrocrino Metab 2002;87:2013-2017.

22. Tomeo CA, Rich-Edward JW, Michels KB, et al. Reproducibility and validity of maternal recall of pregnancy related events. Epidemiology 1999;10:774-777. 
23. Statistics Canada. Joint Canada/United States survey of health: Findings and public-use microdata file. Analytical report, 2002-2003. Available at www.statscan.gc.ca

24. Caplan LS, McQueen DV, Qualters JR, Leff M, Garrett C, Calonge N. Validity of women's self-report of cancer screening test utilization in a managed care population. Cancer Epidemiol Biomarkers Prev 2003;12:1182-1187.

25. Tadman N, Colantonio A. Women and traumatic brain injury: Role changes and related health outcomes. Centre for Research and Women's Health Annual Graduate Student Research Day, 2005.

26. Riddell L, Greenberg K, Meister J. We're women, too: Identifying barriers to gynaecologic and breast health care of women with disabilities. British Columbia Centre of Excellence for Women's Health, Vancouver, BC, 2003.

27. Stein K, Allen N. Cross-sectional survey of cervical cancer screening in women with learning disability. BMJ 1999;318: 641.

28. Altman B, Bernstein A. Disability and health in the United States, 2001-2005. Hyattsville, MD: National Center for Health Statistics, 2008.

29. Uysal S, Hibbard MR, Robillard D, Pappadopulos E, Jaffe M. The effect of parental traumatic brain injury on patenting and child behavior. J Head Trauma Rehabil 1998;13:57-71.

30. Sander AM. A cognitive behavioral intervention for family members of persons with TBI. In: Zasler ND, Katz DI, Zafonte RD. Brain injury medicine. New York: Demos Medical Publishing, 2006:1117-1130.

31. Mukherjee D, Reis JP, Heller WH. Women living with traumatic brain injury: Social isolation, emotional functioning and implications for psychotherapy. Women Ther 2003; 26:3-26.

32. Agha A, Rogers B, Sherlock M, et al. Anterior pituitary dysfunction in survivors of traumatic brain injury. J Clin Endocrinol Metab 2004;80:4929-4936.
33. Tanriverdi F, Senyurek H, Unluhizarci K, Selcuklu A, Casanueva FF, Kelestimur F. High risk of hypopituitarism after traumatic brain injury: A prospective investigation of anterior pituitary function in the acute phase and 12 months after trauma. J Clin Endocrinol Metab 2006;91:2105-2111.

34. Bondanelli M, Ambrosio Mr, Zatelli MC, De Marinis L, degli Uberti EC. Hypopituitarism after traumatic brain injury. Eur J Endocrinol 2005;152:679-691.

35. Leal-Cerro A, Flores JM, Rincon M, et al. Prevalence of hypopituitarism and growth hormone deficiency in adults long term after traumatic brain injury. Clin Endocrinol 2005;62: 525-532.

36. Benvenga S, Campenni A, Ruggeri RM, Trimarchi F. Hypopituitarism secondary to head trauma. I Clin Endocrinol Metab 2000;85:1353-1361.

37. Sipski ML. Sexual function in women with neurologic disorders. Phys Med Rehabil Clin North Am 2001;12:79-90.

38. Grossman WF, Sanfield JA. Hypothalamic atrophy presenting as amenorrhea and sexual infantilism in a female adolescent. A case report. J Reprod Med 1994;39:738-740.

39. Bavisetty S, Bavisetty S, McArthur DL, et al. Chronic hypopituitarism after traumatic brain injury: Risk assessment and relationship to outcome. Neurosurgery 2008;62:10801094.

Address correspondence to: Angela Colantonio, Ph.D., O.T. Reg. (ON) Saunderson Family Chair in Acquired Brain Injury Research University of Toronto, Toronto Rehabilitation Institute 160-500 University Ave. Toronto, Ontario M5G 1V7 Canada

E-mail: angela.colantonio@utoronto.ca 